\title{
Missense mutations in the insulin promoter factor-1 gene predispose to type 2 diabetes
}

\author{
Wendy M. Macfarlane, ${ }^{1}$ Timothy M. Frayling, ${ }^{2}$ Sian Ellard, ${ }^{2}$ Julie C. Evans, ${ }^{2}$ Lisa I.S. Allen, ${ }^{2}$ \\ Michael P. Bulman, ${ }^{2}$ Susan Ayres, ${ }^{2}$ Maggie Shepherd, ${ }^{2}$ Penny Clark, ${ }^{3}$ Ann Millward, ${ }^{4}$ \\ Andrew Demaine, ${ }^{4}$ Terence Wilkin, ${ }^{4}$ Kevin Docherty, ${ }^{1}$ and Andrew T. Hattersley ${ }^{2}$ \\ ${ }^{1}$ Department of Molecular and Cell Biology, Institute of Medical Sciences, University of Aberdeen, Foresterhill, \\ Aberdeen AB25 2ZD, United Kingdom \\ ${ }^{2}$ Department of Diabetes and Vascular Medicine, School of Postgraduate Medicine and Health Sciences, \\ University of Exeter, Exeter EX2 5AX, United Kingdom \\ ${ }^{3}$ Regional Endocrine Laboratory, Selly Oak Hospital, University of Birmingham, Birmingham B29 6JD, United Kingdom \\ ${ }^{4}$ Plymouth Postgraduate Medical School, Plymouth University, Plymouth, Devon PL6 8BH, United Kingdom
}

Address correspondence to: Andrew T. Hattersley, Department of Diabetes and Vascular Medicine,

School of Postgraduate Medicine and Health Sciences, University of Exeter, Barrack Road, Exeter EX2 5AX, United Kingdom.

Phone: 011-44-1392-403082; Fax: 011-44-1392-403027; E-mail: A.T.Hattersley@exeter.ac.uk.

Wendy M. Macfarlane, Timothy M. Frayling, and Sian Ellard contributed equally to this work.

Received for publication May 28, 1999, and accepted in revised form August 25, 1999.

The transcription factor insulin promoter factor-1 (IPF-1) plays a central role in both the development of the pancreas and the regulation of insulin gene expression in the mature pancreatic $\beta$ cell. A dominant-negative frameshift mutation in the IPF-l gene was identified in a single family and shown to cause pancreatic agenesis when homozygous and maturity-onset diabetes of the young (MODY) when heterozygous. We studied the role of IPF-1 in Caucasian diabetic and nondiabetic subjects from the United Kingdom. Three novel IPF-1 missense mutations (C18R, D76N, and R197H) were identified in patients with type 2 diabetes. Functional analyses of these mutations demonstrated decreased binding activity to the human insulin gene promoter and reduced activation of the insulin gene in response to hyperglycemia in the human $\beta$-cell line Nes2y. These mutations are present in $1 \%$ of the population and predisposed the subject to type 2 diabetes with a relative risk of 3.0. They were not highly penetrant MODY mutations, as there were nondiabetic mutation carriers $25-53$ years of age. We conclude that mutations in the IPF-1 gene may predispose to type 2 diabetes and are a rare cause of MODY and pancreatic agenesis, with the phenotype depending upon the severity of the mutation.

J. Clin. Invest. 104:R33-R39 (1999).

\section{Introduction}

Type 2 diabetes affects over 100 million people worldwide and is a major cause of morbidity and mortality. Genetic factors are important in the etiology of type 2 diabetes, but there has been little progress in defining the major genes involved in this complex disease, except in the autosomal dominant subtype maturity-onset diabetes of the young (MODY). MODY is caused by mutations in the genes encoding the glycolytic enzyme glucokinase $(1,2)$ and the transcription factors hepatocyte nuclear factor- $1 \alpha(\mathrm{HNF}-1 \alpha)(3), \mathrm{HNF}-$ $4 \alpha(4), \mathrm{HNF}-1 \beta$ (5), and insulin promoter factor-1 (IPF-1) (6). There is no evidence to suggest that mutations in the MODY genes are significantly involved in the etiology of non-MODY, type 2 diabetes.

The $\beta$-cell homeodomain transcription factor IPF-1 (also known as PDX1/IDX1/STF1/IUF1) is a candidate gene for type 2 diabetes. IPF- 1 is required for normal development of the pancreas, as it is central to the commitment of the gut endoderm to a pancreatic fate (7), the specification of endocrine/exocrine function (8), and the final definition of the $\beta$-cell phenotype (9). In the mature islet, phosphorylation of IPF-1 in response to increased glucose concentrations results in its nuclear translocation, binding to the promoter, and activation of insulin gene transcription (10, 11). Diabetes and $\beta$-cell dysfunction were reported in mice heterozygous for a null mutation (12) or with $\beta$ cell-specific IPF-1 inactivation (13).

The only IPF-1 mutation described in humans is a frameshift mutation (P63fsdelC) with a dominant-negative effect in vitro (14). In this family, a homozygous mutation carrier has pancreatic agenesis (6) and heterozygous mutation carriers have MODY (15). Although this family fits the clinical criteria for MODY, the mean age of diagnosis (35 years) was higher than that seen in patients with $H N F-1 \alpha$ (MODY3) gene mutations (21 years; ref. 16). IPF-1 mutations were not found in French and Japanese MODY subjects $(17,18)$. No mutations were found in the homeodomain and surrounding sequence in 61 Japanese patients with type 2 diabetes (19).

The aim of the present study was to identify mutations in $I P F-1$ in United Kingdom patients with MODY or type 2 diabetes, to investigate the consequences of these mutations at the functional level, and to assess whether these mutations were associated with type 2 diabetes. We postulated that mutations of the IPF-1 gene might cause or predispose to type 2 diabetes, with the phenotype varying according to the severity of the mutation. 

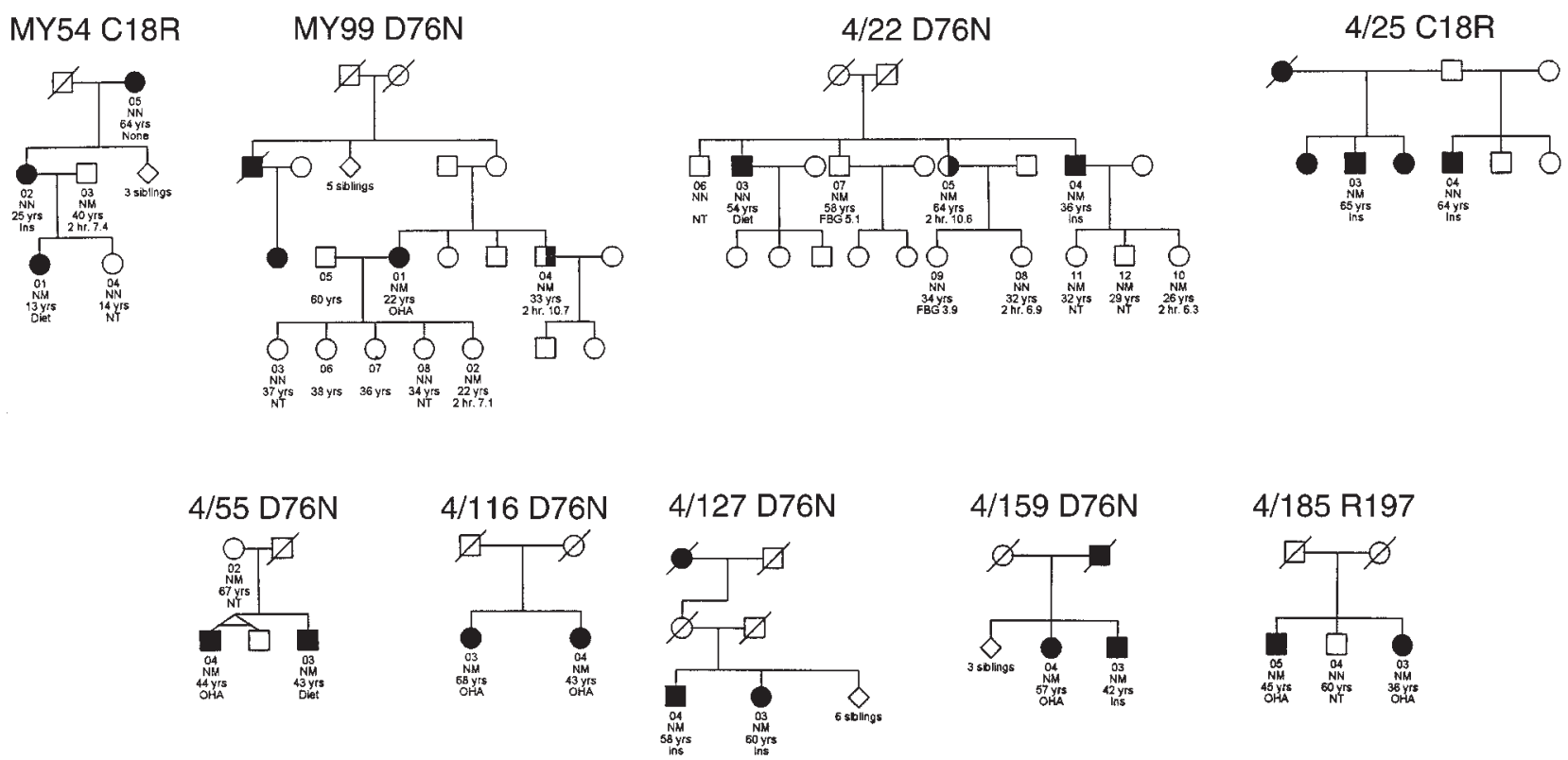

Figure 1

Diabetic families who have probands with IPF-1 mutations. Shown is mutation status within families with either a MODY proband diagnosed before 25 years of age (MY54 and MY99) or type 2 diabetes diagnosed at 35-70 years of age (4/22, 4/25, 4/55, 4/116, 4/127, 4/159, and 4/185). Squares representing diabetic subjects are completely filled, and squares representing patients with impaired glucose tolerance are half-filled. Family number and mutation designation is given above the pedigree. Individual mutation status is given: $N=n o r m a l, M=$ mutation. For affected subjects, age at diagnosis, followed by treatment requirement (OHA = oral hypoglycemic agents; Ins = insulin $)$, is given. For unaffected subjects, age at testing, followed by either 2 -hour glucose value after oral glucose load or by fasting blood glucose value (FBG) or not tested (NT), is given.

\section{Methods}

All studies were approved by the local ethical committee and were conducted in accordance with Declaration of Helsinki principles.

Subjects. All the subjects in this study were Caucasians from the United Kingdom.

Initial mutation screening. DNA was analyzed from 12 subjects with MODY who had been diagnosed before 25 years of age and in whom mutations in the HNF-1 $\alpha, H N F-1 \beta, H N F-4 \alpha$, and $g l u$ cokinase genes had been excluded (MODYx) (20), and from 36 subjects with type 2 diabetes who had been diagnosed before 40 years of age. The type 2 subjects were diagnosed at an average age of $37.6 \pm 4.4$ years (mean \pm $\mathrm{SD}$ ) and were obese (body mass index [BMI] $30.8 \pm 7.8 \mathrm{~kg}^{-2}$ ); $25 \%$ of these subjects were treated with diet, 39\% with oral agents, and $36 \%$ with insulin.

Association studies. Association studies were performed to assess the genetic significance of the 3 missense mutations. This additional mutation testing involved 158 unrelated type 2 diabetic subjects diagnosed between the ages of 35 and 70 years, with at least 1 affected sibling or parent. These subjects were diagnosed at an average age of $55.8 \pm 9.0$ years (mean \pm SD) and had an average BMI of $28.1 \pm 4.9 \mathrm{~kg}^{-2}$; $19 \%$ were treated with diet, $61 \%$ with oral agents, and $20 \%$ with insulin. Two control groups were used: (a) normoglycemic controls: 162 adults over 40 years of age who had normal fasting glucose ( $<5.5 \mathrm{mmol} / \mathrm{L})$ and/or normal hemoglobin $\mathrm{A}_{\mathrm{Ic}}$ and no family history of diabetes; (b) population controls: 509 DNA samples extracted from cord blood from a population series of unrelated births as part of the Earlybird Study cohort from Plymouth, United Kingdom.

Family studies. After identification of a mutation in the proband, all other family members from whom DNA was available were tested. Standard 75-g oral glucose tolerance tests (OGTTs) were performed in 5 nondiabetic mutation carriers, 25-53 years of age, with C18R $(n=1)$ and D76N $(n=4)$, and compared with 10 age- and BMImatched control subjects in whom IPF-1 mutations were not present. Insulin was measured using an immunoenzymometric assay (Medgenix;
Lifescreen, Watford, United Kingdom) calibrated against International Reference Preparation 66/304 (National Institute for Biological Standards and Control, Potters Bar, United Kingdom), with no detectable cross-reactivity with intact proinsulin or $32 / 33$ split proinsulin. Interassay coefficients of variation were less than $10 \%$ over the range 95-1,038 pmol/L. Beta-cell function was compared using the insulinogenic index (the ratio of the increment of insulin to the increment of glucose in the first 30 minutes of the OGTT; ref. 21).

Statistical analysis. Differences in means and proportions were tested principally by Student's $t$ test and the Pearson $\chi^{2}$ test. Relative risk was estimated using odds ratios, and $95 \%$ confidence limits were calculated. Twotailed tests were used.

\section{Molecular genetic methods}

Direct sequencing. The 2 exons and flanking introns of the IPF-1 gene were amplified by PCR from genomic DNA. Exon 1 was amplified using primers described by Hara et al. (18), according to the method of Frayling et 
al. (16), modified to include 9\% DMSO and $100 \mu \mathrm{M}$ 7-Dev2a-dGTP in the reaction mixture. Exon 2 was amplified using primers described by Chèvre et al. (17), with 5\% DMSO added to the reaction mixture. $\mathrm{PCR}$ products were purified using a QIAamp purification column (QIAGEN Ltd., Crawley, United Kingdom) before both strands were sequenced using a BigDye Terminator Cycle Sequencing Kit (Perkin-Elmer Biosystems, Warrington, United Kingdom) and an ABI Prism 377 DNA sequencer (Perkin-Elmer). Heterozygous sequence changes were identified using Sequence Navigator software (Perkin-Elmer).

Mutation screening using restriction site assays. The 3 missense mutations were tested by PCR-RFLP assays. For the C18R mutation, a 117-bp fragment was amplified using the flanking primers 5'-CATGAACGGCGAGGAGCAG-3' and 5'-GCCATGTACAGGC-ACGCAG-3'. The $\mathrm{T} \rightarrow$ C substitution at codon 18 eliminates a digestion site for the restriction enzyme NlaIII. Digestion of products yielded fragments of 50, 61, 4, and $2 \mathrm{bp}$ in the absence of the mutation and 111,4 , and $2 \mathrm{bp}$ in the presence of the mutation. For the R197H mutation, a 287-bp fragment was amplified using the flanking primers 5'-GGTGGAGCTGGCTGTCATGTTG-3' and 5'-AGGGC-TGTGGCGACGCGTAAG-3'. This $\mathrm{G} \rightarrow$ A substitution eliminates a digestion site for the restriction enzyme Fnu4HI and results in an additional fragment of 100 $\mathrm{bp}$ in the presence of the mutation. The primers 5'-TCC-CGTACGAGGTGCCCCCCCTCGCCGIC-3' and 5'-
CGGTTGGGCTCCTCCAGGAC-3' were used to amplify a fragment that included the D76N mutation (E.H. Hani, personal communication). These introduced a nucleotide mismatch into the forward primer (underlined) that creates a restriction site for the enzyme SalI in the absence of the mutation. Digestion produces fragments of 118 and $28 \mathrm{bp}$ in the absence of the mutation and $146 \mathrm{bp}$ in the presence of the mutation. For all 3 assays, PCR was carried out at an annealing temperature of $61^{\circ} \mathrm{C}$. Products were digested at $37^{\circ} \mathrm{C}$ for 3 hours and separated on a 3\% 3:1 agarose/NuSieve gel stained with ethidium bromide.

Functional studies of mutants. The functional activity of the missense mutations C18R, D76N, and R197H was compared with normal IPF-1 by examining 3 critical and well-established IPF1 functional characteristics: (a) phosphorylation-dependent translocation to the $\beta$-cell nucleus upon glucose stimulation; (b) binding activity to the insulin promoter; and (c) ability to activate insulin gene transcription. Each mutation was constructed by sitedirected mutagenesis and expressed in Nes $2 y$ cells. Nes $2 y$ cells are a proliferating human $\beta$-cell line that responds to glucose in the normal physiological range and normally lacks functional levels of the IPF-1 protein (22). Overexpression of normal IPF-1 in these cells has been shown to restore a pattern of glucose regulation of the insulin gene promoter (reporter gene analysis) and glucose regulation of endogenous insulin mRNA levels (Northern blotting), similar to that seen in isolated human islets of Langerhans (22).
Mutagenesis and expression of mutants in Nes $2 y$ cells. Mutagenesis of IPF-1 to create the 3 mutations was performed using the Altered Sites II Mammalian In Vitro Mutagenesis System (Promega UK Ltd., Southampton, United Kingdom) according to the manufacturer's protocols. Mutagenesis of IPF- 1 to create the 3 mutations was performed using the Altered Sites II Mammalian Mutagenesis System according to the manufacturer's protocols. The 3 mutants were created using the following oligonucleotides: (a) 5'-AAGGACCCACGCGCGTTC-3', which introduces a $\mathrm{T} \rightarrow \mathrm{C}$ change within amino acid 18 (C18R); (b) 5'-GCCGACAACCCCGCGGTG-3', which introduces a $\mathrm{G} \rightarrow \mathrm{A}$ change within amino acid 76 (D76N); and (c) 5'CAAAACCGCCACATGAAG-3', which introduces a $\mathrm{G} \rightarrow \mathrm{A}$ mutation within amino acid 197 (R197H). Mutagenesis was confirmed by sequencing of both strands of the mutant plasmids. Mutant proteins were expressed in Nes2y cells directly from the pALTER vector, which uses a eukaryotic cytomegalovirus (CMV) promoter. Plasmid DNA was prepared using the EndoFree Maxi Kit (QIAGEN Ltd.), and transfections were performed using a minimum of 2 separate plasmid preparations.

Nuclear translocation. Analysis of nuclear translocation was performed by Western blotting using a specific IPF-1 antibody (23), which was a kind gift from C.V. Wright (Vanderbilt University, Nashville, Tennessee, USA). Nuclear and cytoplasmic extracts were prepared as described (11), with sam-

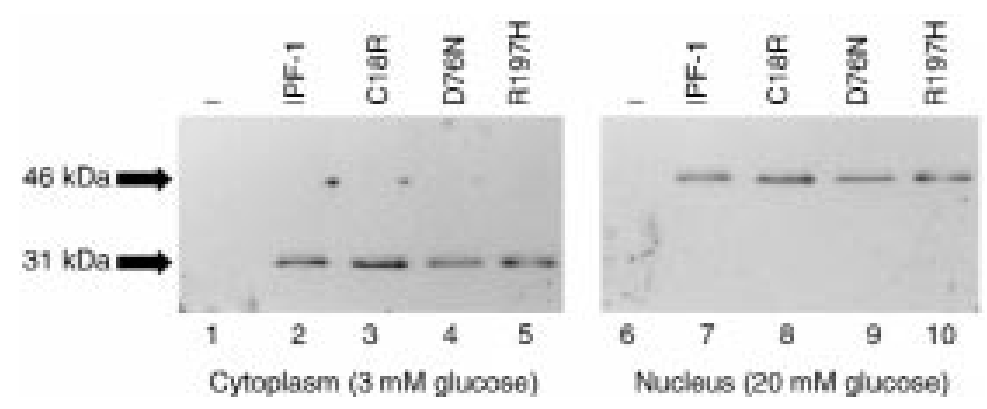

\section{Figure 2}

Localization of IPF-1 mutants. Western blot analysis of cytoplasmic samples (lanes 1-5) or nuclear samples (lanes 6-10) prepared from Nes $2 y$ cells incubated in low $(3 \mathrm{mM})$ or high $(20 \mathrm{mM})$ glucose concentrations. Lanes 1 and 6 represent untransfected Nes $2 y$ cells; lanes 2 and 7 represent cells expressing normal IPF-1; lanes 3 and 8 represent cells expressing C18R; lanes 4 and 9 represent cells expressing D76N; and lanes 5 and 10 represent cells expressing R197H. Analysis was performed using a specific IPF- 1 antibody; $1 \mu \mathrm{g}$ of each extract was used. Results are representative of 3 separate experiments. 

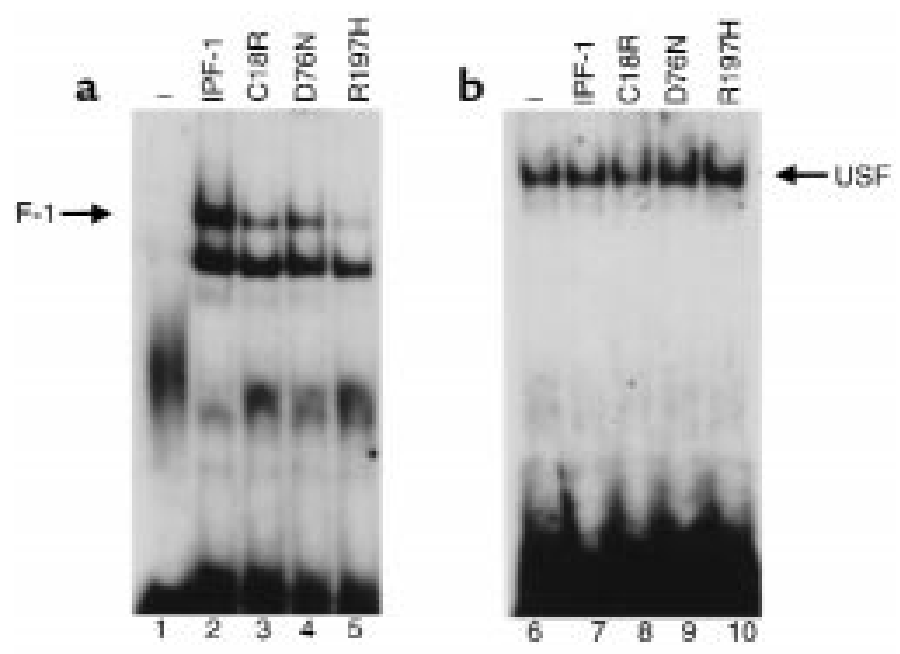

Figure 3
EMSA analysis of binding activity to insulin promoter. (a)
EMSA analysis of IPF-1-binding activity in nuclear extracts
prepared from untransfected Nes2y cells (lane 1), cells
expressing normal IPF-1 (lane 2), C18R (lane 3), D76N
(lane 4), or R197H (lane 5), using the A3 site of the
human insulin gene promoter as a probe. The upper band
(arrow) represents IPF-1-binding activity. An analysis of
$0.5 \mu \mathrm{g}$ of each sample was performed, and the results are
representative of 3 separate experiments. (b) EMSA analy-
sis of USF-binding activity in nuclear extracts prepared
from untransfected Nes2y cells (lane 1) or from cells
expressing normal IPF-1 (lane 2), C18R (lane 3), D76N
(lane 4 ), or R197H (lane 5), using the E2 site of the
human insulin gene promoter as a probe. An analysis of
$0.5 \mu \mathrm{g}$ of each sample was performed, and the results are
representative of 3 separate experiments

ples being equalized for protein concentration. One-microgram samples of cell extract were fractionated by SDS-PAGE and blotted onto enhanced chemiluminescence-nitrocellulose (ECL-nitrocellulose) membrane (Amersham Life Sciences, Buckinghamshire, United Kingdom) and incubated for 60 minutes in a buffer containing $10 \mathrm{mM}$ Tris- $\mathrm{HCl}, \quad 0.05 \%$ (vol/vol) Tween-20, $0.5 \mathrm{M} \mathrm{NaCl}$, and a 1:5000 dilution of anti-IPF-1 antibody. The antigen-antibody complex was then detected by incubating the membrane for an additional $60 \mathrm{~min}$ utes in buffer containing a 1:5,000 dilution of horseradish peroxidaseconjugated anti-rabbit IgG secondary antibody. Quantification was performed using the Phoretix Program II package (Phoretix International, Newcastle, United Kingdom).

Binding activity to insulin promoter by electrophoretic mobility shift assay. Analysis of binding activity was performed by electrophoretic mobility shift assay (EMSA), using the A3 site of the human insulin gene promoter as described previously (10). Nuclear extracts were prepared from untransfected Nes2y cells and from Nes2y cells overexpressing IPF-1, C18R, D76N, or R197H. Extracts containing $0.5 \mu \mathrm{g}$ protein were then incubated with a radiolabeled probe for 20 minutes at room temperature in buffer containing $10 \mathrm{mM}$ Tris- $\mathrm{HCl}$ ( $\mathrm{pH} 7.5), 50 \mathrm{mM}$ $\mathrm{KCl}, 5 \mathrm{mM}$ DTT, $1 \mathrm{mM}$ EDTA, and $5 \%$ (vol/vol) glycerol. Nes2y cells have no detectable IPF-1-binding activity (see
Figure 3, lane 1). Each mutant was compared with normal IPF-1-binding activity. To confirm equal loading of the samples, the same nuclear extracts were analyzed for the binding activity of a second transcription factor, upstream stimulatory factor (USF), which binds to an adjacent site within the human insulin gene promoter (see Figure $3 b$ ). USF-binding activity was comparable in all 5 samples (see Figure 3b, lanes 6-10).

Transcription of the insulin gene. To investigate the ability of the mutant IPF-1 proteins to activate transcription of the insulin gene, cells expressing normal IPF-1, C18R, D76N, or R197H were transfected with pGL-Luc200, a reporter gene construct containing the -60 to -260 region of the human insulin gene promoter LUC200, or with control construct pGL-Luc, lacking the -60 to -260 region. Nes2y cells were grown and transfected as described previously (22). Treatment of transfected cells started with a 5-hour preincubation in RPMI containing 3 $\mathrm{mM}$ glucose. Where appropriate, cells were stimulated for 30 minutes (cell extracts) or 3 hours (reporter gene assays) with $20 \mathrm{mM}$ glucose. Luciferase assays and protein quantitations were performed as described previously (22).

\section{Results}

Mutations identified in the IPF-1 gene. In the initial direct sequencing of subjects with young-onset type 2 diabetes and MODY, we found 3 novel heterozygous missense mutations. A
$\mathrm{T} \rightarrow \mathrm{C}$ transition in codon 18 resulted in the substitution of cysteine by arginine $(\mathrm{C} 18 \mathrm{R})$; a $\mathrm{G} \rightarrow \mathrm{A}$ transition at codon 76 replaced aspartic acid with asparagine (D76N); and a $\mathrm{G} \rightarrow \mathrm{A}$ transition at codon 197 resulted in the substitution of arginine by histidine (R197H) (Table 1). The amino acids altered by the mutations are all conserved in rat, mouse, chicken, frog, and zebra fish.

Association of IPF-1 mutations with type 2 diabetes. The distribution of these mutations in subjects with familial type 2 diabetes and in normoglycemicand population-based controls is shown in Table 1. The C18R and R197H mutations were seen only in diabetic subjects, and $\mathrm{D} 76 \mathrm{~N}$ was more prevalent in diabetic probands compared with controls. Analysis of all 3 mutations in the MODY and type 2 probands revealed a significant association with diabetes (relative risk 3.9; range $1.4-10.8 ; P=0.006$ ). When only the type 2 probands were included in this analysis, the relative risk for all mutations was 3.0 (range 1.0-9.2; $P=$ 0.04 ). It is unlikely that the observed association with diabetes reflects genetic admixture, because there was a suggestion of familial association, with 6 of 7 diabetic full siblings of the type 2 probands inheriting the IPF-1 mutation $(P=0.10)$. Although both $\mathrm{C} 18 \mathrm{R}$ and $\mathrm{D} 76 \mathrm{~N}$ were found in MODY subjects diagnosed before 25 years of age, these mutations did not behave as highly penetrant, causative mutations within these families: they 
do not cosegregate with diabetes (Figure 1), and there were subjects between 25 and 53 years of age with the mutation who were not diabetic, even after testing with an OGTT. There was some suggestion that the $\mathrm{R} 197 \mathrm{H}$ mutation was more severe, because no nondiabetic subject mutation carriers were identified, and the mean age of diagnosis in type 2 diabetic subjects was 40.5 years, compared with 52.5 years for C18R and D76N carriers.

Studies in nondiabetic mutation carriers. The five 25- to 53-year-old nondiabetic subjects with the C18R and D76N mutations had decreased glucose tolerance compared with 10 age- and BMImatched controls (2-hour OGTT: 8.2 vs. $5.7 \mathrm{mmol} / \mathrm{L} ; P=0.02)$. The $\beta$-cell function assessed by the insulinogenic index during an OGTT was similar in both groups (136 vs. $137 \times 10^{-9} ; P=0.99$ ).

Functional activity of C18R, D76N, and $\mathrm{R} 197 \mathrm{H}$

Phosphorylation-dependent translocation to the $\beta$-cell nucleus upon glucose stimulation. All 3 mutants, like native IPF-1 (11), were expressed at equivalent levels in the $\beta$-cell cytoplasm as a $31-\mathrm{kDa}$ inactive protein in low-glucose conditions and were activated and translocated to the nucleus under high-glucose conditions (Figure 2).

Binding activity to the insulin promoter. All 3 mutants showed decreased binding activity to the $\mathrm{A} 3$ site of the human insulin gene promoter (Figure 3): C18R, 60-70\%; D76N, 60-70\%; and $\mathrm{R} 197 \mathrm{H}$, less than $50 \%$ of the activity of normal IPF-1. As in previous studies
(11), binding specificity was confirmed by antibody and oligonucleotide competition EMSA analysis. Samples were equalized for protein content, and confirmation of equal loading was performed by analysis of the binding activity of an unrelated basal transcription factor USF (Figure 3b) (22).

Activation of insulin gene transcription. To investigate the ability of the mutant IPF-1 proteins to activate transcription of the insulin gene, we transfected cells expressing normal IPF-1, C18R, D76N, or R197H with pGL-Luc200, a reporter gene construct containing the -60 to -260 region of the human insulin gene promoter LUC200 (Figure 4). When normal IPF-1 is expressed in these cells (Figure 4b), the control construct (pGLLuc, which lacks the promoter fragment) is unaffected, but the LUC200 activity increases 5 -fold in high glucose compared with low glucose, because of IPF-1 activation of the insulin promoter. The expression of mutant forms of IPF-1 did not alter the control construct or LUC200 activity in low glucose, but did show a reduction in LUC200 activation at high glucose levels (C18R, 70\%; D76N, 72\%; R197H, 46\%; Figure 4, c, d, and e, respectively) compared with normal IPF-1.

\section{Discussion}

We have identified 3 novel mutations in the $\beta$-cell transcription factor IPF- 1 that are associated with type 2 diabetes. All 3 mutations (C18R, D76N, and $\mathrm{R} 197 \mathrm{H}$ ) result in reduced binding of the protein to the insulin gene promoter and decreased insulin gene tran-

Table 1

The prevalence of IPF-1 mutations in diabetic and control populations from the United Kingdom

\begin{tabular}{|c|c|c|c|c|c|}
\hline & \multirow[t]{2}{*}{$n$} & \multicolumn{3}{|c|}{ Mutation } & \multirow[t]{2}{*}{ Total } \\
\hline & & C18R & D76N & R197H & \\
\hline \multicolumn{6}{|l|}{ Diabetic subjects } \\
\hline MODYX & 12 & $1(8.3 \%)$ & $1(8.3 \%)$ & $0(0 \%)$ & $2(16.7 \%)^{\prime}$ \\
\hline Initial familial type 2 cohort & 36 & $0(0 \%)$ & $1(2.8 \%)$ & $1(2.8 \%)$ & $2(5.6 \%)^{\mathrm{B}}$ \\
\hline Follow-up familial type 2 cohort & 158 & $1(0.6 \%)$ & $3(1.9 \%)$ & $0(0 \%)$ & $4(2.5 \%)$ \\
\hline Total & 206 & $2(1 \%)^{B}$ & $5(2.4 \%)$ & $1(0.5 \%)$ & $8(3.8 \%)^{A}$ \\
\hline \multicolumn{6}{|l|}{ Controls } \\
\hline Normoglycemic & 166 & 0 & $2(1.2 \%)$ & 0 & $2(1.2 \%)$ \\
\hline Population & 509 & 0 & $5(1.0 \%)$ & 0 & $5(1.0 \%)$ \\
\hline Total & 675 & 0 & $7(1.0 \%)$ & 0 & $7(1.0 \%)$ \\
\hline
\end{tabular}

scription in response to hyperglycemia. To our knowledge, this is the first evidence that mutations in IPF-1 can predispose to type 2 diabetes as well as cause MODY (6), and the different penetrance of the mutations is reflected in their in vitro activity.

The reduction in function of the missense mutations identified in type 2 diabetic patients is not as severe as that seen with the P63fsdelC frameshift mutation, which resulted in MODY (6). The less severe C18R and D76N mutations occur within the $\mathrm{NH}_{2}$-terminal and first proline-rich domains of IPF-1, which primarily play a role in transcriptional activation (24). It is surprising, therefore, that these mutations resulted in a decrease in binding activity. Nonetheless, the moderate decrease in binding activity is reflected in the effect these mutations have on insulin gene transcription, which was moderately decreased by about $25-30 \%$ compared with normal IPF-1. In addition, $\mathrm{Lu}$ et al. also report that mutations located $\mathrm{NH}_{2}$-proximal to the homeodomain of IPF-1 can modulate DNAbinding activity (25). Clinically, these mutations appeared less penetrant than the R197H mutation, which is located within the DNA-binding homeodomain of the protein and demonstrates the least activity in the functional assays $(\sim 50 \%$ of that observed with normal IPF-1).

The mechanism by which IPF-1 mutations predispose to type 2 diabetes has not been fully established. The failure to see a difference in $\beta$-cell function, despite significantly worse glucose tolerance, probably reflects the small numbers in the study rather than the presence of normal $\beta$-cell function. In addition to the insulin gene, IPF-1 also regulates the expression of other $\beta$-cell genes, including GLUT-2 (26), glucokinase (27), and islet amyloid polypeptide (IAPP) (28). From our data, we cannot be certain that the reduction in insulin gene transcription in response to hyperglycemia seen in vitro is sufficient to explain the glucose intolerance and diabetes seen in subjects who are heterozygous for these mutations, because defective regulation of these other genes and insulin may also contribute to $\beta$-cell dysfunction. 


\section{Figure 4}

Analysis of the transcriptional activation of the insulin gene in Nes2y cells. Relative luciferase activity from control construct pGL-Luc (LUC) or from a construct containing the -60 to -260 region of the human insulin gene promoter PGL-Luc200 (LUC200) in 3 $\mathrm{mM}$ (open bars) or $20 \mathrm{mM}$ (filled bars) glucose. Reporter gene activity was analyzed in untransfected Nes2y cells (a), or in Nes2y cells expressing normal IPF-1 (b), C18R (c), D76N (d), or R197H (e). Values are shown as relative luciferase activity standardized against protein content. Values represent an average from 6 replicates; error bars represent SD. Each set of values has been reproduced in 3 separate experiments.

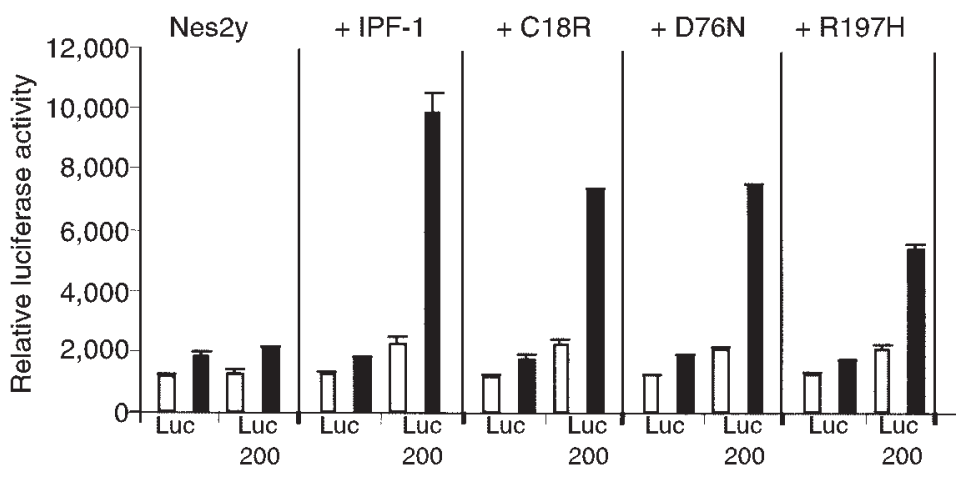

To our knowledge, our studies provide the first evidence that mutations in the pancreatic transcription factor IPF-1 may predispose to type 2 diabetes. The missense mutations we have described meet many criteria for predisposing to type 2 diabetes: they reduce function in vitro; they occur within a critical gene in which a severe mutation has been shown to cause young-onset diabetes; they are associated with diabetes with a relative risk of 3.0; and they have young adult mutation carriers who are not diabetic but show impaired glucose tolerance. Genetic admixture is unlikely to be the explanation for the association with diabetes, because even with a small number of siblings and families examined, there was a trend toward association in a familial study. Additional large association studies are essential to further assess the prevalence and role of these and other IPF-1 mutations in other populations. Our reported relative risks are unreliable because of the low prevalence of the mutations, and our study used type 2 subjects selected for a strong family history of diabetes (42\% had at least 1 affected parent, compared with $23 \%$ found in a community survey of 4,811 type 2 subjects) (A. Hattersley et al., unpublished observations). Only 1 previous study has looked at the role of IPF- 1 in type 2 diabetes; no mutations were found in 61 Japanese subjects, but the whole gene was not sequenced (19).

Although mutations were found in 2 probands who conformed to MODY criteria, in contrast to the previously described P63fsdelC (6), C18R and D76N do not behave as highly penetrant MODY mutations, because they did not cosegregate with diabetes within families. Further evidence that these mutations do not cause MODY comes from the finding that for both mutations there are mutation carriers 25-53 years of age who are not diabetic, even after testing with an OGTT.

We conclude that mutations in IPF-1, with a moderate reduction of in vitro activity, may predispose to type 2 diabetes. To our knowledge, this is the first observation that mutations in a single gene can not only cause MODY, but can also frequently predispose to type 2 diabetes, with the phenotype depending on the severity of the mutation.

\section{Acknowledgments}

The authors thank the families who made this study possible. The patients were involved in collections made in Exeter, United Kingdom by the British Diabetic Association. We gratefully acknowledge the help of Moira Murphy and Simon Howell. We thank Diane Jarvis for technical assistance. This work was supported by the British Diabetic Association, the Wellcome Trust, the Medical Research Council, the Royal Devon \& Exeter National Health Service (NHS) Healthcare Trust, the University of Exeter, and DIRECT. T.M. Frayling is supported by the South and West NHS Research Directorate as a Career Scientist.

1. Froguel, P., et al. 1992. Close linkage of glucoki nase locus on chromosome $7 p$ to early-onset noninsulin-dependent diabetes mellitus. Nature. 356:162-164.

2. Hattersley, A.T., et al. 1992. Linkage of type 2 diabetes to the glucokinase gene. Lancet 339:1307-1310.

3. Yamagata, K., et al. 1996. Mutations in the hepatic nuclear factor 1 alpha gene in maturity-onset diabetes of the young (MODY3). Nature. 384:455-458.

4. Yamagata, K., et al. 1996. Mutations in the hepa- tocyte nuclear factor 4 alpha gene in maturityonset diabetes of the young (MODY1). Nature. 384:458-460.

5. Horikawa, Y., et al. 1997. Mutation in hepatocyte nuclear factor-1b gene (TCF2) associated with MODY. Nat. Genet. 17:384-385.

6. Stoffers, D.A., Ferrer, J., Clarke, W.L., and Habener, J.F. 1997. Early-onset type-II diabetes mellitus (MODY4) linked to IPF1. Nat. Genet. 17:138-139.

7.Johnsson, J.L., Carlsson, T., Edlund, T., and Edlund, H. 1994. Insulin promoter factor 1 is required for pancreas development in mice. Nature. 371:606-609.

8. Swift, G.H., et al. 1998. An endocrine-exocrine switch in the activity of the pancreatic homeodomain protein PDX1 through formation of a trimeric complex with PBX1 and MRG1 (MEIS2). Mol. Cell. Biol. 18:5109-5120.

9. Ohlsson, H., Karlsson, K., and Edlund,T. 1993. IPF1, a homeodomain-containing transactivator of the insulin gene. EMBO J. 12:4251-4259.

10. Macfarlane, W.M., et al. 1997. The p38/reactiviating kinase mitogen activated protein kinase cascade mediates the activation of the transcription factor IUF1 and insulin gene transcription by high glucose in pancreatic beta-cells. J. Biol. Chem. 272:20936-20944.

11. Macfarlane, W.M., et al. 1999. Glucose stimulates translocation of the homeodomain transcription factor PDX1 from the cytoplasm to the nucleus in pancreatic $\beta$-cells. J. Biol. Chem. 274:1011-1016.

12. Dutta, S., Bonner-Weir, S., Montminy, M., and Wright, C. 1998. Regulatory factor linked to lateonset diabetes? Nature. 392:560.

13. Ahlgren, U., Jonsson, J., Jonsson, L., Simu, K., and Edlund, H. 1998. Beta-cell-specific inactivation of the mouse Ipf1/Pdx1 gene results in loss of the beta-cell phenotype and maturity onset diabetes. Genes Dev. 12:1763-1768.

14. Stoffers, D.A., Stanojevic, V., and Habener, J.F. 1998. Insulin promoter factor-1 gene mutation linked to early-onset type 2 diabetes mellitus directs expression of a dominant negative isoprotein. J. Clin. Invest. 102:232-241.

15. Stoffers, D.A., Zinkin, N.T., Stanojevic, V., Clarke, W.L., and Habener, J.F. 1997. Pancreatic agenesis attributable to a single nucleotide deletion in the human IPF1 gene coding sequence. Nat. Genet. 15:106-110.

16. Frayling, T., et al. 1997. Mutations in the hepatocyte nuclear factor 1 alpha gene are a common cause of maturity-onset diabetes of the young in the United Kingdom. Diabetes. 46:720-725.

17. Chèvre, J.C., Hani, E.H., Stoffers, A., Habener, J.F., and Froguel, P. 1998. Insulin promoter factor 1 gene (IPF1) is not a major cause of maturityonset diabetes of the young in French Caucasians. Diabetes. 47:843-844.

18. Hara, M., et al. 1998. Mutations in the coding region of the insulin promoter factor 1 gene are not a common cause of maturity-onset diabetes of the 
young in Japanese subjects. Diabetes. 47:845-846. 19. Inoue, H., et al. 1996. Isolation, characterization, and chromosomal mapping of the human insulin promoter factor 1 (IPF-1) gene. Diabetes. 45:789-794.

20. Beards, F., et al. 1998. Mutations in hepatocyte nuclear factor 1 beta are not a common cause of maturity-onset diabetes of the young in the U.K. Diabetes. 47:1152-1154.

21. Kosaka, K., Kuzuya, T., Hagura, R., and Yoshinaga, H. 1996. Insulin response to oral glucose load is consistently decreased in established noninsulin-dependent diabetes mellitus: the usefulness of decreased early insulin response as a predictor of non-insulin-dependent diabetes mellitus. Diabet. Med. 13(Suppl. 6):S109-S119.
22. Macfarlane, W.M., et al. 1997. Impaired expression of the transcription factor IUF1 in a pancreatic cell-line derived from a patient with persistent hyperinsulinaemic hypoglycaemia of infancy (nesidioblastosis). FEBS Lett. 413:304-308.

23. Peshavaria, M.L., et al. 1994. Xlhox 8, an endoderm specific Xenopus homeodomain protein, is closely related to a mammalian insulin gene transcription factor. Mol. Endocrinol. 8:806-816.

24. Peshavaria, M., Henderson, E., Sharma, A. Wright, C.V.E., and Stein, R. 1997. Functional characterisation of the transactivation properties of the PDX1 homeodomain protein. Mol. Cell. Biol. 17:3987-3996.

25. Lu, M., Miller, C., and Habener, J. 1996. Func- tional regions of the homeodomain protein IDX1 required for transactivation of the rat somatostatin gene. Endocrinology. 137:2959-2967.

26. Waeber, G., Thompson, N., Nicod, P., and Bonny, C. 1996. Transcriptional activation of the GLUT2 gene by the IPF1/STF1/IDX1 homeobox factor. Mol. Endocrinol. 10:1327-1334.

27. Watada, H., et al. 1996. PDX1 induces insulin and glucokinase gene expression in alpha-TC1 clone 6 cells in the presence of betacellulin. Diabetes. 45:1478-1488.

28. Serup, P., et al. 1996. Induction of insulin and islet amyloid polypeptide production in pancreatic islet glucagonoma cells by insulin promoter factor 1. Proc. Natl. Acad. Sci. USA. 93:9015-9020. 